\section{HELPING DEVICES OF WALKING}

\section{Dr. Irina Petruşcă ${ }^{1}$}

${ }^{1}$ Institutul Național de Recuperare, Medicina Fizica şi Balneoclimatologie

Abstract

Helpful resources are devices used to increase the independence of patients.

Batavia and Hammer have established four important criteria in the evaluation and selection of supported devices (1): 1. Effectiveness, 2. Accessibility, 3. Efficiency, 4. Reliability.

The goals of helpful walking means are to improve balance, providing a sensitive feedback, reducing pain.

The stick enlarges the support basis and decreases stress on the inferior affected limb opposite $(5,6,9)$ and can download up to $25 \%$ of body weight of the patient.

The crutch has two points in contact with the body providing a stability better than stick (5,6,10,11). Axillary crutches have the main advantage that allows you to download up to $80 \%$ weight, providing a better trunk than nonaxilare allowing a transfer of 40-50\% of patient weight.

Walk framework is the best device for the patient confused or having an unsteady gait can be used for early recovery work. Has the advantage that it provides maximum support of the patient.

Wheelchair is used by patients who ambulatia is impossible or possible but for short distances. All wheelchairs need a system that stands unique and should provide adequate stability and increase functionality.

Orthotic of lower limb aims to keep normal relations, both static and dynamic balance between joints-knee-ankle-foot. They can be used to correct an incorrect walk pattern and to increase efficiency of walking.

Type of chosen helper device depend on the degree of assistance in general, as disability is greater, the more complexity of chosen device is greater $(2,3,4,5,6,7)$.
Helpful means are devices used to increase the degree of independence of patients and can be classified as follows:

- mobility devices/ambulate

- devices for ADL's and self-care

- devices for the hearing, seeing, speaking, safe.

Batavia and Hammer have established four important criteria in the evaluation and selection of supported devices (1):

1. Effectiveness

2. Accessibility

3. Efficiency

4. Reliability.

Type of chosen helper device depend on the degree of assistance in general, as disability is greater, the more complexity of chosen device is greater $(2,3,4,5,6,7)$.

Auxiliary driving means objectives are:

- Imbunătătiirea echilibrului:

- Providing a sensitive feedback

- Alleviate pain

Deficientele care necesita dispozitive ajutatoare de mers sunt :

- Slight deficiencies of equilibrium/ stability stick with a support points;

- Moderately deficiency of equilibrium $/$ stability - stick with 4 / 4 of

- Moderate to severe deficiency - hemi frame / frame

- muscle strength decrease in the both inferior limbs - bilateral crutches or frame (eventually with wheels)

- Severe impairment of stability - frame (possibly with wheels)

- Punch / hand function impaired - platform framework

- Difficulty in climbing stairs - stairs climbed special frame (8).

Stick enlarges the support basis and decreases stress on the affected limb opposite $(5,6,9)$ and can download up to $25 \%$ of body weight of the patient. Stick length is important because improper use leads to the formation of an incorrect walk pattern. To determine the optimal size is measured in distance from tip of the stick great trochanter with the patient standing, the elbow flexion of 20 degrees. 


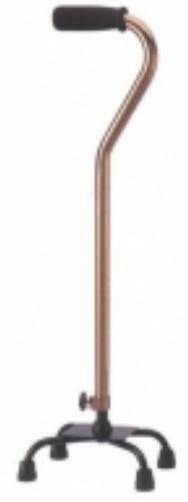

Figure 1. The sitck

The instructions for use: the side opposite the affected limb, while the stick will move the opposite limb, the first step being made by the unaffected limb. The climbing and descending stairs rule is 'up good, down the river' (up and down the free limb to ill limb, or possibly just after it).

There are several types of sticks:

- Stick in C, J, standard with a single point of support

- Stick with functional gripping or resistive

- Stick with $3 / 4$ points of support.

Indications for use of the stick: degenerative diseases, neurological disorders, orthopedic problems, etc..

The crutch has two points in contact with the body providing a stability better than stick $(5,6,10,11)$. There are two commonly used types of crutches: axillary and nonaxilare. Axillary crutches have the main advantage that allows downloading up to $80 \%$ weight, providing a better support of trunk than nonaxilare . Patients should be advised of the possibility of brachial neuropathy compression and advised to avoid all the rest and support the body weight crutches.

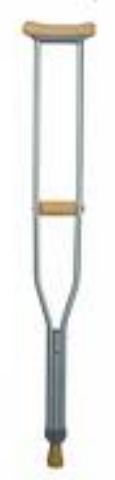

Figure 2. The crutch

Crutches length is calculated as follows: distance from the axillary fold of $15 \mathrm{~cm}$ side of the finger 5, play the hand that you will be placed so that the elbow flexion to be 30 degrees, fist in full extension and flexion finger. Manner of use is: collect axillary piece between the arms and chest and push down with your hand for hand play.

Nonaxilare crutches allow a transfer of $40-50 \%$ of patient weight providing a good trunk control. Crutches Lofstrand / Canadian are the most popular and commonly used bilaterally. Have the advantage of ensuring a safe and easy ambulate (12), substitute easily the stick provide but provide lower support for than ambulate axillary crutches .

Kenney stick (Wooden forearm orthosis) - looks like axillary crutches, but the proximal end with a leather band placed around the proximal portion of the forearm. Are indicated to patients who have a particularly high strength on upper limb but low on the distal.

Carja cu platforma este folosita de pacientii $\mathrm{cu}$ o prehensiune deficitara si celor $\mathrm{cu}$ flexum la nivelul cotului, avand avantajul ca greutatea pacientului este suportata in majoritate de antebrat in loc de mana cum se intampla in cazul celorlalte tipuri de carje.

Everett crutch (triceps weakness orthosis for) - looks like a crutch but ends proximal axillary in the third average arm and who are two cuffs at elbow level to keep the elbow in extension.

The walk framework is the best device for the patient confused or having an unsteady gait due to disorders of equilibrium can be used for early recovery work. Has the advantage that it provides maximum support of the patient. Among the disadvantages are: slow and awkward walk, creates an incorrect posture and walk pattern, has limited use inside and can not be safely used for climbing and descending of stairs.

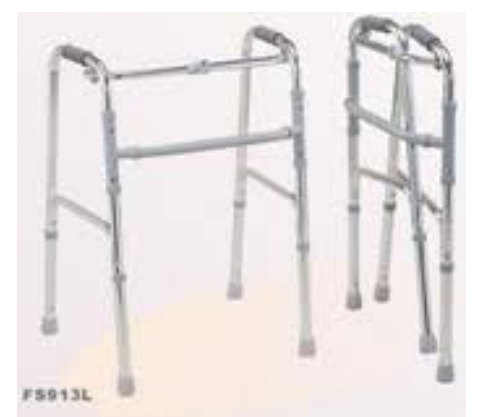

Figure 3. The framework walk

Manner of use and frame size are important: is made placement of $30 \mathrm{~cm}$ in front of the patient, partially surrounding the patient, and 
the ideal height should provide of 20 degrees flexion at elbow level.

The rolling stock presents wheels walk at the limbs level that $t$ promotes frame; strength and equilibrium are needed for handling as movemenrequired by the standard. But has the disadvantage that it can create instability if not used properly and require supervised training sessions to ensure patient safety.

Framework walk with support for forearms is indicated for patients with deformities in the hand, wrist and forearm, pain or those with flexum elbow. The only downside of this is heavy.

The framework walk forup and down of stairs is indicated young patients with paraplegia. This device requires a good balance and good strength in the upper limbs.

The wheelchair is used by patients who ambulatia is impossible or possible but for short distances. All wheelchairs need a system that stands unique to be:

- to provide adequate support patient in a sitting position

- to maintain the orthopedic alignment and adjust any fixed asymmetry

- to ensure adequate stability and increase functionality

- to ensure proper distribution of pressure, comfort and increase tolerance to stay in a sitting position (13).

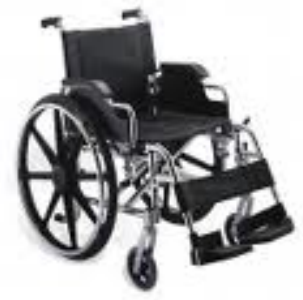

Figure 4. Wheelchair

A defective distribution of pressure can lead to the development of pressure eschars. Setting in motion the armchair can be done manually or electrically.

Orthoses are external devices applied to a segment of the body to prevent or correct malfunctions of that segment. The purpose of orthotic limb consists of:

- restoration of functions and normal abilities by controlling movement, and deformity correction of any malfunctions of different compensation -obtaining of a comfortabledevice, easy to wear and esthetic as possible. (15)

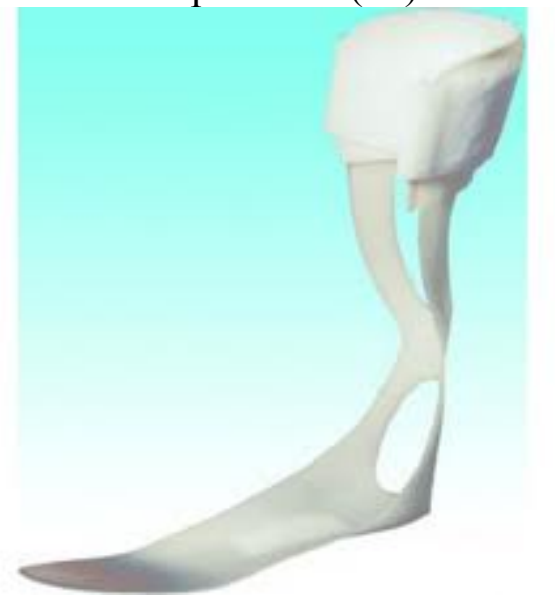

Figure 5. The ankle orthosis (limb)

Orthotic of the inferior limb aims to keeping normal relations, both static and dynamic between hip-knee-ankle-foot joints. They can be used to correct an incorrect walk pattern and walking to increase efficiency.

Types of orthoses depending on the segment which is applied to (American Orthotic and Prosthetic Association):

$-\mathrm{FO}=$ foot orthosis

$-\mathrm{KO}=$ knee orthosis

$-\mathrm{HO}=$ hip orthosis

$-\mathrm{AFO}=$ ankle foot orthosis

-KAFO $=$ orthosis for knee-ankle-foot

- HKAFO= hip-knee ankle-foot orthosis

- $\mathrm{RGO}=$ reciprocal walk orthosis.

Inferior limbs orthoses should be used only in specific management of selected disorders such as: loading orthoses, orthotics for fracture orthosis for joint deformities, congenital dislocation of hip orthosis for.

\section{Conclusions}

The purpose of all these helpful walk devices presented here is to increase the independence of patients by taking and transmits body weight and provide support. Them recommendation is made taking into account the necessary degree of balance (equilibrium) and the proportion of discharging the needed (discharge weight) (16).

In general, the degree of disability is higher, so requires a complex device walk. 


\section{References:}

1. Batavia DI, Hammer CS. Toward the development of consumer-based action for the evaluation of assistive devices. J Rehabil Res Dev. 1990;27:419-24.

2. Burgess E, Alexander A. Mobility aids. In: Atlas of Orthopedics. St. Louis, Mo: CV Mosby; 1975.

3. Deathe AB, Hayes KC, Winter DA. The biomechanics of canes, crutches, and walkers. Crit Rev Phys Rehab Med. 1993;5:15-29.

4. Jebsen RH. Use and abuse of ambulation aids. JAMA. Jan 2 1967;199(1):5-10. [Medline].

5. Varghese G. Crutches, canes, and walkers. In: JB Redford, ed. Orthotics Etcetera. 2nd ed. Baltimore, Md: Williams \& Wilkins; 1980:453-63.

6. Hennessey WJ, Johnson EW. Lower limb orthoses. In: Physical Medicine and Rehabilitation. 2nd ed. Philadelphia, Pa: WB Saunders Co; 2000:326-52.

7. Rudin L, Lisa S. Basic Rehabilitation Techniques. Germantown, Md: Aspin System Corp; 1977.

8. Divakara Kedlaya, MBBS; Chief Editor: Consuelo T Lorenzo, MD more...- Assistive Devices to improve independence http://emedicine.medscape.com/article/32524 7-overview

9. Blount WP. Don't throw away the cane. J Bone Joint Surg Am. Jun 1956;38-A(3):695708. [Medline].

10. Deaver GG. What every physician should know about the teaching of crutch walking. $\mathrm{J}$ Am Med Assoc. Feb 18 1950;142(7):470-2. [Medline].

11. The classic. Art, history and the crutch, by Sigmund Epstein, in Ann. Med. Hist., 1937, 9:304. Clin Orthop Relat Res. 1972;89:4-9. [Medline]

12. Slavens BA, Frantz J, Sturm PF, et al. Upper extremity dynamics during Lofstrand crutchassisted gait in children with myelomeningocele. J Spinal Cord Med. 2007;30 Suppl 1:S165-71. [Medline]. [Full Text].
13. Requejo PS, Kerdanyan G, Minkel J, et al. Effect of rear suspension and speed on seat forces and head accelerations experienced by manual wheelchair riders with spinal cord injury. J Rehabil Res Dev. 2008;45(7):98596. [Medline].

14. Cinteza D, Poenaru D. Ortezarea in recuperarea medicala Bucuresti, 2004 (1-18).

15. Robert H Meier III, MD Lower Limb Orthotics and Therapeutic Footwear http://emedicine.medscape.com/article/31483 8-overview

16. Mincer AB. Assistive devices for the adult patient with orthopaedic dysfunction. Why physical therapists choose what they do. Orthop Nurs. Jul-Aug 2007;26(4):226-31; quiz 232-3. [Medline]. 